(昭和 34 年 11 月 20 日受理)

低温重合PVC濃厚溶液の性質

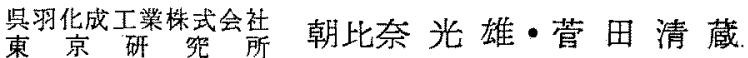

\section{THE PROPERTIES OF CONCENTRATED SOLUTION OF POLY (VINYL CHLORIDE) POLYMERIZED AT LOW TEMPERATURE}

By Mitsuo Asahina and Seizo Sugata

(Kureha Kasei Co. Ltd., Tokyo Laboratory, Hyakunin-Cho, Shinjuku-Ku, Tokyo, Japan)

The two $\mathrm{P}$ V C samples, polymerized at different temperatures were fractionated by precipitation method, and the viscosities of concentrated solutions of these fractions were measured by coaxial cylindrical viscometer, at the temperature ranging from 35 to $75^{\circ} \mathrm{C}$.

The viscosities of the concentrated solution of two samples are proportional to the degree of polymerization $\left(P_{W}\right)$ in power of 3.4, and to the concentration in the power of 5 , but the apparent: activation energy of flow of the sample, polymerized at low temperature (low temp. polymer) is higher than the polymers polymerized at high temperature (high temp. polymer). The degree of entanglement in the solution of low temperature polymer is much higher than that of high temperature polymer.

(Received November 20, 1959)

\section{1. 緒言}

低温重合で得られたポり筀化ビニル（PVC）分子が， 普通 PVCのそれに比してょり高い立体規則性を有し， また枝分れが少いことは既に島内1) Greisenth waite, によつて指摘されていることであるが，そのような分子 鎖の規則性に起因して，低温重合 PVC は溶液中で用直 な形態をとり4)，固態に执いても硬い性格を示し，同時 により高い結晶性を持つ早。筆者ら によって，低温重合 PVC の溶液中に却ける “分子鎖の 执がり”が普通 PVCのそれに比して著るしく大きいこ そについて述べた。希薄溶液に和ける分子鎖の形態が， 濃㝵溶液の場合にす敷えんでをるとすれば，“拡がり”の 大きな低温重合 PVC は普通PVCに比して，濃厚溶液 に和ける分子镍間の重なり合い，すなわち分子镍間の “からみ合い”の数が多いと考兄られる。

本報ではいわゆる“分子鎖のからみ合い“の問題を主 眼に招き，低温重合 PVC 濃厚溶液の特異性について枱 討する。

\section{2. 実験について}

この寒験に用いた主な重合物は, 通常の㮩濁重合によ つたもの（S-3）および低温乳化重合によつて得たもの (XF-13) である。れらの重合温度および重合度は第 8表就よび第1表に示した。これらは，いずれるテトラ
ヒドロフラン溶液から水で分別沈殿し，それをれ 9 10 個の重合度の異る区分を得，それらを实験の試料とした が，一回の分別では寒駼火充分な量の区分を得ることが できなからたので，数回に分けて分別し，各分別によっ て得られた区分を適当に混合して実験仁供した。

これら試料の重量平均重合度 $\left(\bar{P}_{W}\right)$ を第 1 表にまとめ たが，この值は $3 \sim 8 \mathrm{~g} / /$ の濃度範囲でテトラヒドロフラ ン溶液の $30^{\circ} \mathrm{C}$ に数ける粘度を測定して極限粘度数 [ を求め，また数回の陚料について光散乱实驗を行なつて $\bar{P}_{W}$ 実測し，それに他の分別区分についての寒業結:

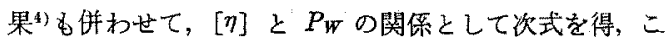
の式から計算によって求めた。

$$
[\eta]=1.35 \times 10^{-3} P_{W} W^{0.6}
$$

これらの試料は封管中で $130^{\circ} \mathrm{C}$ に加熱して，14\%（重 量) のンクロヘキサノン溶液とし，その溶液の粘度を 35 $75^{\circ} \mathrm{C}$ の温度域にわたつて測定した。粘度の測定には 共軸二重円筒型粘度計を用いたが，低温重合 PVCの溶 液はこの程度の濃度でも長時間室温に放置すると，次第 に搆造粘性を增し，ついにはゲル化するので，測定はな るべく溶解㨁後に行なう上う意を払つた。すべての場合 外筒の回転数を連続的に変えて測定したが，第 1 园にそ の一例を示す如く，外筒の回転数々内简の权しれ角は常 に直線関保をほ满足するので, 構造粘甠は無視するこ とができた。

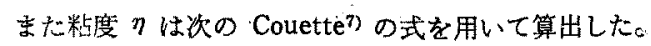




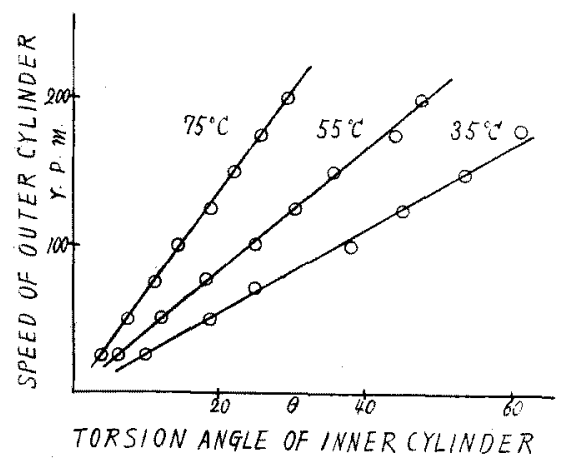

Fig. 1. Speed-angle relationships for $\mathrm{XF}-13_{-2}$ solution.

第 1 表 試料 $[\eta]$ と $\bar{P}_{W}$

\begin{tabular}{l:c|c|c|c|c}
\hline 区分名 & {$[\eta]$} & $\bar{P}_{W}$ & 区分名 & {$[\eta]$} & $\bar{P}_{W}$ \\
\hline $\mathrm{S}-3$ & 0.1208 & 1,800 & $\mathrm{XF}-13^{\prime}$ & 0.1031 & 1,380 \\
$\mathrm{~S}-3_{-1}$ & 0.1650 & 3,020 & $\mathrm{XF}-13_{-1}$ & 0.1620 & 2,880 \\
$\mathrm{~S}-3_{-2}$ & 0.1437 & 2.400 & $\mathrm{XF}-13_{-2}$ & 0.1412 & 2,290 \\
$\mathrm{~S}-3_{-3}$ & 0.1300 & 2,140 & $\mathrm{XF}-13_{-3}$ & 0.1307 & 2,040 \\
$\mathrm{~S}-3_{-4}$ & 0.1165 & 1,700 & $\mathrm{XF}-13_{-4}$ & 0.1223 & 1,820 \\
$\mathrm{~S}-3_{-5}$ & 0.0885 & 1,070 & $\mathrm{XF}-13_{-5}$ & 0.0953 & 1,200 \\
$\mathrm{~S}-3_{-6}$ & 0.0792 & 890 & $\mathrm{XF}-13_{-6}$ & 0.0643 & 620 \\
$\mathrm{~S}-3_{-7}$ & 0.0605 & 565 & $\mathrm{XF}-13_{-7}$ & 0.0522 & 450 \\
$\mathrm{~S}-3_{-8}$ & 0.0583 & 530 & $\mathrm{XF}-13_{-8}$ & 0.0597 & 410 \\
$\mathrm{~S}-3_{-9}$ & 0.0554 & 490 & $X \mathrm{X}-13_{-9}$ & 0.0318 & 195 \\
$\mathrm{~S}-3_{-10}$ & 0.0430 & 320 & & & \\
\hline
\end{tabular}

$$
\begin{gathered}
\eta=T . S / \omega \\
S=\left(1 / R^{2}-1 / R^{2}{ }_{1}\right) 4 \pi h \\
T: \text { トルク } \\
\omega: \text { 外简の角速度 } \\
R_{1}: \text { 外筒の半径 } \\
R_{2}: \text { 内筒の半径 } \\
h: \text { 内筒の浸漬長 }
\end{gathered}
$$

\section{3. 実験結果および考察}

上述の如くして測定した各試料溶液の各温度に和子る 粘度を第 2 表扎よび第 3 表にぬとめた。

\section{1 見掛けの活性化熱の啈合温度依存性}

第 2 表括よび第 3 表の測定值から，粘舆の対数 $\log \eta$

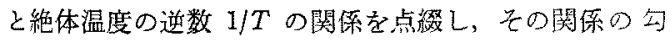

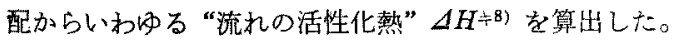

\begin{tabular}{|c|c|c|c|c|c|}
\hline 韵料 & 35 & 45 & 55 & 65 & 75 \\
\hline$S-3_{-1}$ & 9,734 & 6,838 & 5,398 & 4,405 & 3,674 \\
\hline$S-3_{-2}$ & 4,714 & 3,745 & 2,982 & 2,444 & 2,115 \\
\hline $\mathrm{S}-3_{-3}$ & 2,775 & 2,219 & 1,807 & 1,408 & 1,165 \\
\hline $\mathrm{S}-3_{-4}$ & 1,641 & 1,261 & 995 & 792 & 651 \\
\hline$S-3_{-5}$ & 498 & 396 & 327 & 265 & 226 \\
\hline$S-3_{-6}$ & 440 & 352 & 326 & - & 203 \\
\hline$S-3_{-7}$ & 164 & 134 & 110 & 92 & 79 \\
\hline$S-3_{-8}$ & 136 & 111 & 90 & 75 & 60 \\
\hline $\mathrm{S}-3_{-4}$ & - & - & - & - & - \\
\hline$S-3_{-10}$ & 60 & 48 & 38 & 31 & 26 \\
\hline
\end{tabular}
この関係はわれわれの实験の温度籁囲では, 全域にわた つて直線関係方成立し， $\Delta H \div$ の温度依存性任認的られ

\begin{tabular}{|c|c|c|c|c|c|}
\hline 料 & 35 & 45 & 55 & 65 & 75 \\
\hline$X F-13-1$ & - & - & - & - & - \\
\hline$X F-13_{-2}$ & 6,758 & 5,224 & 4,214 & 3,256 & 2,577 \\
\hline $\mathrm{XF}-13_{-3}$ & 3,323 & 2,560 & 2,020 & 1,579 & 1,297 \\
\hline$X F-13 \ldots$ & 3,640 & 2,682 & 2,079 & 1,641 & 1.315 \\
\hline$X F-13_{-\bar{x}}$ & 836 & 674 & 500 & 393 & 355 \\
\hline$X F-13_{-0}$ & 198 & 160 & 129 & 105 & 88 \\
\hline$X F-13_{-\gamma}$ & 98 & 77 & 62 & 52 & 42 \\
\hline$X F-13_{-8}$ & 80 & 65 & 55 & 48 & - \\
\hline$X F-13_{-9}$ & 33 & 29 & - & - & - \\
\hline
\end{tabular}
なかつた。このよ化して求的た各試料溶液の $\Delta H \neq$ を $\bar{P}_{W}$ に対して点綴し，第2図にはとめた。図に見られる
符 2 春 $S-3$, 分别物の粘度 (C.P)

第 3 表 XF-13，分別物の粘度 (C.P)

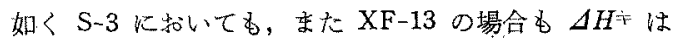
低重合度側で著るしく重合度に依存し，高重合度側で 重合度に殆んど供存せず一定の值を示すにいたるが，一 般に XF-13 S S 石。

\section{$3 \cdot 2$ 粘度と重合度の関係}

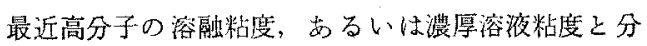
子量の関係について多くの研究がなされ一定温度, 一定

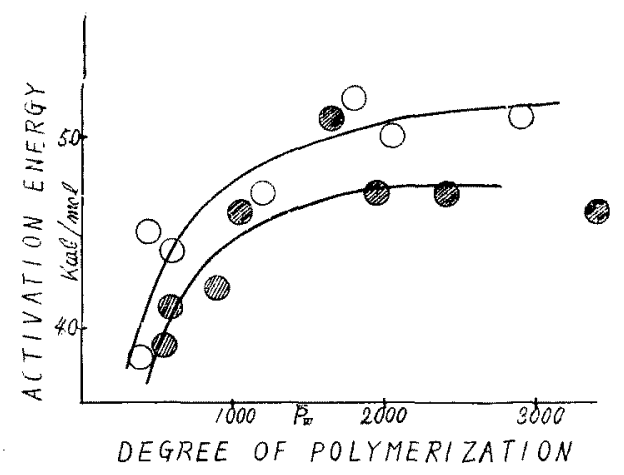

Fig.2. Apparent activation energy of flow $\mathrm{XF}-13, \mathrm{~S}-3$ 


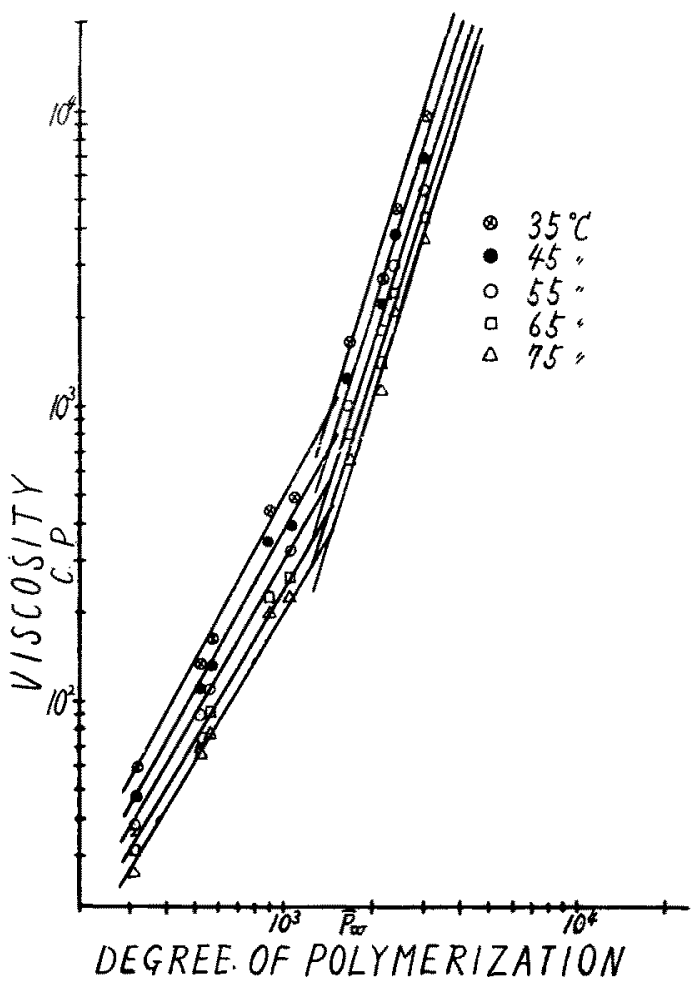

Fig. $3 \eta-\bar{P}_{W}$ relationships for ordinary PVC

浀度では粘度の対数と分子量の対数との関係は系状分子 の化学精造とは無関係にある分子量 $M_{c}$ （または重合度 $\left.P_{c}\right)$ に相当する点で相交る 2 值楾で表わされ， $\mathbb{P}_{c}$ 以上 の分子量ては次の関係が一般に成立することが知られて (. $3^{9}$

$\log \eta=3.4 \log P_{W}+K$

PVC の場合もその例外ではなく，第 2 表特よび第3 表の結果から $\log \eta$ と $\log \bar{P}_{W}$ の関係を点緅すると第 3

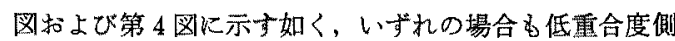
の直線関係と高重合度側の淔線関保に分れるが，高重合 度側の直線の勾配は䄪 3.4 となり重合温度および測定温 度に無風係でする。また 2 值線の交点に相当する重合

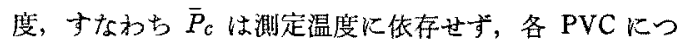
いてそれぞれ一定の值亦しているが，重合温度の高い

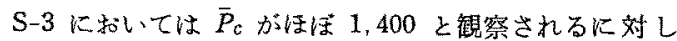

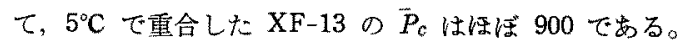
F. Bueche $\mathrm{e}^{102)}$ によると $\bar{P}_{\mathrm{c}}$ 以下の分子量では分子鎖は 平妁 2 個以上の“からみ合い”持つことができす，必 然的にすべての分子が完全に連結し合うことはてき支 い。各分子が互に連結可能の極限の重合度が $P_{c}$ であ。

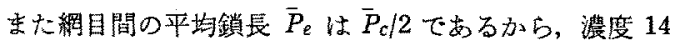

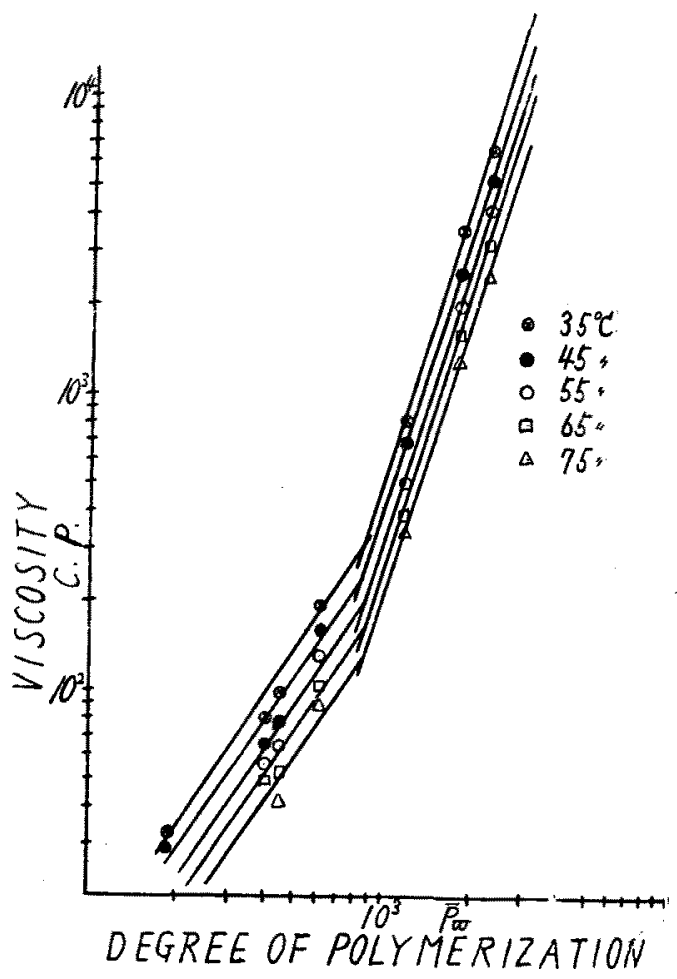

Fig. 4. $\eta-\bar{P}_{W}$ relationships for $\mathrm{PVC}$, polymerized at $5^{\circ} \mathrm{C}$

\%のシクロツキサノン溶派の場合， $\bar{P}_{e}$ はそれぞれ次の 値となる。

S-3, $\quad \vec{P}_{e}=700 ; \mathrm{XF}-13, \quad \bar{P}_{e}=450$

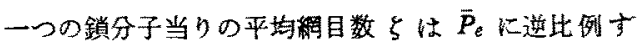
るとして差支壳ないから同じ重合度, 同じ濃度の此較で は低温重合 PVCは普通 PVCに比して, 溶浓中の分子 鎖の“から合い”が多いと考えてよい。また溶液の濃 度と $\bar{P}_{c}$ の間汇次の関係 ${ }^{11,12)}$ があるから，濃度が高く なつた場合の結晶化，その他の構造変化を無視すれば

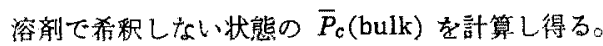

$$
\begin{aligned}
& v_{2} \bar{P}_{c}=\text { constant } \\
& \left.v_{2}=\left(C / \rho_{2}\right) /\{100-C) / \rho_{1}+C / \rho_{2}\right\} \\
& \rho_{1}: \text { : 溶媒の比重 } \\
& \rho_{2}: \text { 溶賀の比重 } \\
& C: \text { 溶顀の重量百分率 }
\end{aligned}
$$

ここで非晶状態にある PVC の比重 $\rho_{2}$ を1.40 と L $\rho_{1}$ (シクロキサノン) を 0.88 として $\bar{P}_{c}$ (bulk) を計 算すると，S-3 の㵵合 $\bar{P}_{c}($ bulk $)=130, X F-13$ の場合 $\bar{P}_{c}($ bulk $)=84$ となる。故に任意の濃度に扣ける $\bar{P}_{c}$ は 各重合物について次式によつて計算できる。 
S-3, $\quad \bar{P}_{c}=130 \times 1 v_{2}$

$\mathrm{XF}-13, \quad P_{c}=84 \times 1 / v_{2}$

前述の如く $\bar{P}_{c}$ 以上の重合度では $\log \eta-\log P_{W}$ の関係 は直線であり，その勾配は 3.4 になるので, 粘度の重合 度依存性住次式によつ示てされる。

$$
\begin{array}{lll}
\text { S-3, } & \eta=k^{\prime} \vec{P}_{W^{3.4}} & \bar{P}_{W}>130 \times 1 / v_{2} \cdots(7) \\
\mathrm{XF}-13, & \eta=k^{\prime \prime} \dot{P}_{W}{ }^{3.4} & \bar{P}_{W}>84 \times 1 / v_{2} \cdots \cdots(8)
\end{array}
$$

\section{3 粘度と㳻度の関係}

濃厚溶液粘度の濃度依存性を調ベる目的て S-3, XF13 の未分別物につき，種々灙度を变えて粘度を测定し た。この場合も前述の分別区分の時と同様に実験の籍团 内ではせん断応力とせん断速度の関係は直線となり，棈 造粘性は無視できたが，その結果を第 4 表および第 5 表 にまとめた。

各濃度における粘度の対数を濃度の対数に対して点緅 すると第 5 図の結果が得られる。すなわりいずれの試料 についても, $\log \eta-\log C$ の関係は直線となり, 重合温

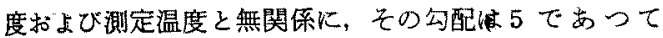
Ferry ${ }^{13)}$ の他の重合物についての結果と一致する。

\section{4 分子鎖の“加み合い”之紡禾性}

溶夜から系条を形成し得るためには，关の溶液が分子 鎖の，からみ合い”によるいわゆる絧目構造をとつてい なければならず，一つの分子鎖について少くとも平均 2 個の核目点の存在が必要である。

シタロへキサノンの $14 \%$ 溶液の場合には, 普通 PVC で $\bar{P}_{W}=1,400$ 以上，杰た重合温度が $5{ }^{\circ} \mathrm{C}$ の PVC では $\bar{P}_{W}=900$ 以上でその条件が満足されることは前述した
第 4 表 S-3 溶液の粘度 $\eta(\mathrm{C} . \mathrm{P})$

\begin{tabular}{r|rr|r|c}
\hline $\begin{array}{c}\text { 浀度\% } \\
\text { 温度 }{ }^{\circ} \mathrm{C}\end{array}$ & \multicolumn{1}{|c|}{8} & 10 & 12 & 18 \\
\hline 35 & 186 & 495 & 1,160 & 8,287 \\
45 & 159 & 362 & 896 & 6,530 \\
55 & 126 & 293 & 679 & 5,050 \\
65 & 105 & 244 & 566 & 4,092 \\
75 & 85 & 206 & 472 & 3,256
\end{tabular}

\begin{tabular}{|c|c|c|c|c|}
\hline 温度 ${ }^{\circ} \mathrm{C}$ & 8 & 10 & 12 & 12 \\
\hline 35 & 143 & 359 & 943 & 3,744 \\
\hline 45 & 112 & 283 & 731 & 2,943 \\
\hline 55 & 90 & 230 & 551 & 23,68 \\
\hline 65 & 71 & 192 & 448 & 1,898 \\
\hline 75 & - & 157 & 358 & - \\
\hline
\end{tabular}

第 5 表 XF-13 溶液の粘度 $\eta(\mathrm{C} . \mathrm{P})$

通りである。高た任意の濃度 Cに対しては，

普通 PVC， $\quad \bar{P}_{W}>130 \times 1 / v_{2}$

$5^{\circ} \mathrm{C}$ 重合 $\mathrm{PVC}, \quad \bar{P}_{W}>84 \times 1 / v_{2}$

の場合に系条を形成し得る条件が与えられる。われわれ はこのいわゆる“からみ合い”之紡系性の関係に蛙ける 低温重合 PVC の特異性を明らかにする目的で, 前述の 各 PVC 区分の $14 \%$ シク口人キサノン溶液を紡系し, 系条の形成される様子を調べた。すなわら第6図に示す 如き簡単な紡系装置を用い，紡系液の自重によつて，丸 タノールの凝固浴中心紡出し凝固の様子を観察した。

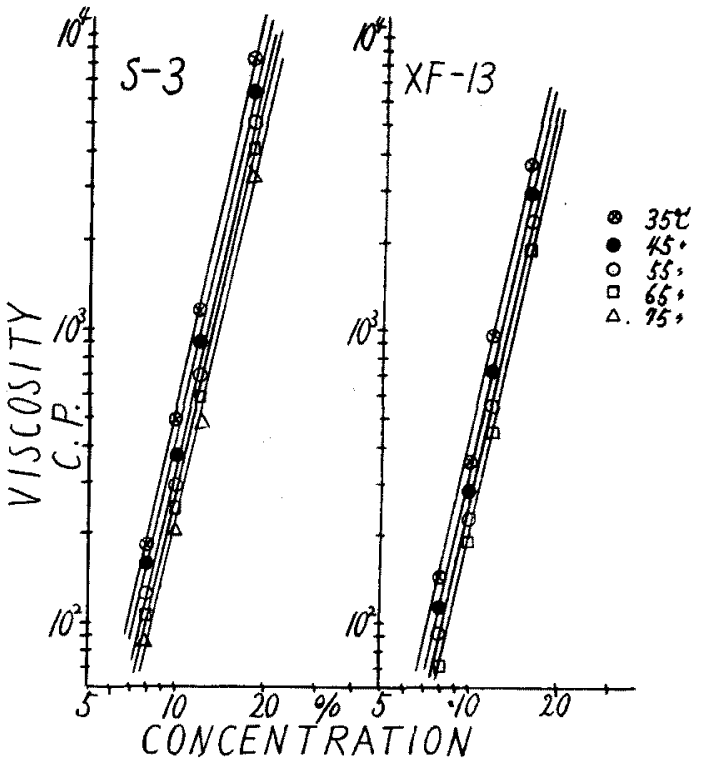

Fig. 5. Dependency of $\eta$ on polymer concentration

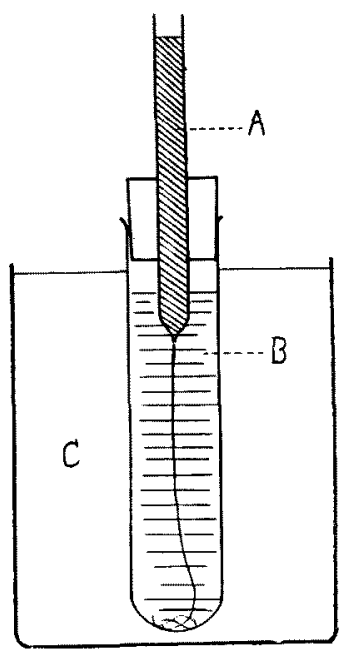

Fig.6. Spinng apparatus
A Solution
B Coagulation bath C $40^{\circ} \mathrm{C}$ hot bath 
重合度が $\bar{P}_{c}$ 以下の区分の溶液は，紡出之同時に四散 して凝固浴が白渢することを予想したが，シクロへキサ ノンのメタノール中への拡散が比較的遅く，そのために 凝固浴の藷るしい白濁は見られなからた。しかし重合度 が低くなると紡出された綿の自重によつて，紡出口の部 分で切断し，連結的な糸条を形成することは不可能にな る。

その様子を第 6 表に示した。表に見られる如く，䊉系 の困難になる鎖舆は，前述の $\dot{P}_{C}$ 々定性的な一致を示し ている。

第6 表 $\bar{P}_{\mathrm{W}}$ と紡紋性

\begin{tabular}{|c|c|c|c|}
\hline \multicolumn{2}{|c|}{ S-3 } & \multicolumn{2}{|c|}{$X F-13$} \\
\hline $\bar{P}_{W}$ & 紡 系性 & $\bar{P}_{W}$ & 紡来性 \\
\hline 3,020 & O.K & 2,880 & o. K \\
\hline 2,400 & $" 1$ & 2,290 & $"$ \\
\hline 2,140 & $"$ & 2,040 & $"$ \\
\hline 1,700 & "I & 1,820 & $"$ \\
\hline 1,070 & N. G & 1,200 & " \\
\hline 890 & $" 1$ & 620 & N. G \\
\hline 565 & "I & 450 & $" 1$ \\
\hline 530 & "I & 410 & $" 1$ \\
\hline 490 & $\prime \prime$ & 195 & $"$ \\
\hline 320 & 11 & & \\
\hline
\end{tabular}

第 7表 XF-13-4 溶液の䇥度と紡系性

\begin{tabular}{c|c|c|c|c|c}
\hline 濃度\% & 0.5 & 1 & 2 & 4 & 8 \\
\hline 絬系性 & N.G & N.G & N.G & O.K & O.K \\
\hline
\end{tabular}

$14 \%$ 溶液の $\bar{P}_{c}$ から任意の灙度に打ける $\bar{P}_{c}$ は（5） 式から算出できるが，今仮に重合温度 $5^{\circ} \mathrm{C}$ ののにいい て，濃度 $3 \%$ の場合の $\bar{P}_{c}$ を計算すると， $\bar{P}_{c}=2190$ と なる。実際に， $\bar{P}_{W}=1820$ XF-13-4の種々濃度に和忛る 紡系性を調べた結果は第 7 表の如く，4\% 以下の濃度で は紡糸不能であり，上記計算の結果と活涪一致する。

かくの如く $\bar{P}_{c}$ と紡糸性の関係は明らかであり，また 普通 PVCに比して，5C で重合したPVC は紡糸可能 な重合度および濃度がより低くなることが明らかとなつ たが，重合の温度が更に低くなるにつれて，その傾向は
第 8 褺 重合温度と $C_{\mathrm{crlt}}$

\begin{tabular}{c|r|r|r}
\hline 試 & \multicolumn{1}{c|}{ S-3 } & XF-134- & \multicolumn{1}{|c}{$F-2$} \\
\hline 重合温度 ${ }^{\circ} \mathrm{C}$ & 55 & 5 & -15 \\
$\bar{P}_{W}$ & 1,800 & 1,820 & 1,320 \\
$C_{\text {orit }} \%$ & $4 \sim 8$ & $2 \sim 4$ & $0.5 \sim 1$ \\
\hline
\end{tabular}

より著るしくなる。第8表には重合温度のそれぞれ異る 3 種の試料沉ついて，その紡系可能な極限の濃度 $C_{\text {erit }}$ を示した。

3.5 むす

以上濃厚溶液の諸性質について市服のPVC と，低温 重合 PVC 比較検討した。その結果次の点を明らかに することができた。

1），低温重合 PVC 濃厚溶液の流れの活性化熱は，一 般に普通 PVCのそれより高い值を示す。

2）重合温度の低いものは，濃厚溶液に括汀る分子鎖 の“からみ合い”が多く，高い温度で重合した普通 のPVCに比して，ょり低い重合度またはょり低い 濃度での紡系が可能である。

（付記）

本研究は低温重合 PVC 性質に関寸る研究の一部であ り，京都大学教授桜田一郎博士に種々御指導を頂いた。 ここに深甚の謝意を表します。また本研究の発表を許可 された会社当局に感謝します。

\section{文献}

1) 島内 5 ; 高分子, 8，202 (1959)

2) Greisenth waite; Chem. Ind., p. 719 (1958)

3) Greisenth waite; Chem. Ind., p.1114 (1959)

4) 朝比奈, 小林, 佐藤; 高分子討論会 (1959)

5）朝比奈，田畑；高分化，17，325(1960)

6) 渡辺, 掘田；工化，61，1322（1958）

7) 例光ば T. Alfrey; Mechanical behavior of high Polymers (1948)

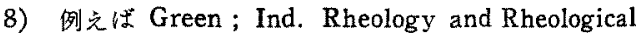
Structure (1949)

9) 例艺ば Eirich； Rheology (Volume 1) (1956)

10) F. Bueche ; J. Chem. Phys., 20, 1959 (1952)

11) F. Bueche; $J$. Appl. Phys., 24, 423 (1953)

12) F. Bueche; J. Appl. Phys., 26, 738 (1955)

13) J.D.Ferry ; J. Colloid Sci., 12, 400 (1957) 